\title{
Chemical composition and in vitro evaluation of the cytotoxic and antioxidant activities of supercritical carbon dioxide extracts of pitaya (dragon fruit) peel
}

Hui Luo ${ }^{1,3+}$, Yongqiang Cai ${ }^{1+}$, Zhijun Peng ${ }^{1}$, Tao Liu ${ }^{1}$ and Shengjie Yang ${ }^{2,3 *}$

\begin{abstract}
Background: Hylocereus polyrhizus and Hylocereus undatus are two varieties of the commonly called pitaya fruits, and pitaya fruits have gained popularity in many countries all over the world. However, studies on chemical composition and the nutritional quality of pitaya flesh peel are limited.

Results: Extracts of pitaya (H. polyrhizus and $H$. undatus) peel were extracted by supercritical carbon dioxide extraction, and analyzed by gas chromatography-mass spectrometry analysis. Their cytotoxic and antioxidant activities were investigated. The main components of $H$. polyrhizus extract were $\beta$-amyrin (15.87\%), $a$-amyrin (13.90\%), octacosane (12.2\%), $\gamma$-sitosterol (9.35\%), octadecane (6.27\%), 1-tetracosanol (5.19\%), stigmast-4-en-3-one (4.65\%), and campesterol (4.16\%), whereas H. undatus were $\beta$-amyrin (23.39\%), $\gamma$-sitosterol (19.32\%), and octadecane (9.25\%), heptacosane (5.52\%), campesterol (5.27\%), nonacosane (5.02\%), and trichloroacetic acid, hexadecyl ester (5.21\%). Both of the two extracts possessed good cytotoxic activities against PC3, Bcap-37, and MGC-803 cells ( $\left(C_{50}\right.$ values ranging from 0.61 to $0.73 \mathrm{mg} / \mathrm{mL}$ ), and the activities of their main components were also studied. Furthermore, these extracts also presented some radical scavenging activities, with $I_{50}$ values of 0.83 and 0.91 $\mathrm{mg} / \mathrm{mL}$, respectively.
\end{abstract}

Conclusion: This paper provides evidence for studying the chemical composition of supercritical carbon dioxide extracts of pitaya peel and their biological activity.

\section{Background}

Pitaya is often called "dragon fruit" following its bright red skin with green overlapping fins covering the fruit, which has gained popularity in many countries all over the world [1]. Three varieties that have been commercialized are Hylocereus polyrhizus, which has red-skinned fruit with red flesh, Hylocereus undatus (Red pitaya), which has red-skinned fruit with white flesh, and Hylocereus megalanthus (Yellow

\footnotetext{
*Correspondence: yangsj2003@gmail.com

${ }^{\dagger}$ Equal contributors

${ }^{2}$ Research Institute of Traditional Chinese Medicine, Yangtze River

Pharmaceutical Group Beijing Haiyan Pharmaceutical Co., Ltd, Beijing 102206, P R China

${ }^{3}$ State key Laboratory Breeding Base of Green Pesticide and Agricultural Bioengineering, Key Laboratory of Green Pesticide and Agricultural Bioengineering, Ministry of Education, Guizhou University, Guiyang 550025, P R China

Full list of author information is available at the end of the article
}

pitaya), which has yellow-skinned fruit with white flesh [2]. They belong to the vine cacti from the subfamily Cactoideae of the tribe Cacteae, and are native to the tropical forest regions of Mexico and Central and South America [3]. $H$. polyrhizus and $H$. undatus have recently drawn much attention from growers worldwide, because of their powerful antioxidative activity [4-6]. Betanin, phyllocactin, hylocerenin, and betacyanin with 5-O-glycosides or 6-O-glycosides have been discovered in many species of the Cactaceae family $[7,8]$. Furthermore, these types of compounds are responsible for many pharmacological activities such as antitumor, antioxidant, and anti-inflammatory actions. The objectives of this study were to evaluate the nutritional quality of pitaya flesh peel and study whether the peel of pitaya, the waste product from juice manufacture, could be utilized as a potential alternative for various sources of nutrients or antioxidants to improve human health. 
The aim of the present study was, as a first step, to determine the chemical composition of supercritical carbon dioxide extracts of the peel of pitaya (H. polyrhizus and $H$. undatus) by gas chromatography-mass spectrometry (GCMS) analysis. In a second step, we examined the in vitro cytotoxic and antioxidant activities of the two extracts by MTT and DPPH assays, respectively. We compared their activities with the activity of the major component of each extract sample. To our knowledge, there are no published reports on the chemical compositions, cytotoxic and antioxidant activities of supercritical carbon dioxide extracts of the pitaya (H. polyrhizus and $H$. undatus) peel.

\section{Results and discussions}

\section{Chemical composition of supercritical carbon dioxide} extract

The pale yellowish extracts of the peel of $H$. polyrhizus and $H$. undatus were obtained by supercritical carbon dioxide extraction, with yield of $1.81 \%$ and $1.25 \%$, respectively. These extracts were analyzed by GC-MS. The identified constituents of the two extracts and their retention time are shown in Table 1. All the compounds are arranged in the order of their elution from the HP5-MS column.

Regarding the chemical composition of the two extracts tested, they were shown to be complex mixtures

Table 1 Chemical composition of supercritical carbon dioxide extracts of pitaya peel

\begin{tabular}{|c|c|c|c|c|}
\hline \multirow[t]{2}{*}{ No. } & \multirow[t]{2}{*}{ Compounds } & \multirow[t]{2}{*}{$\mathrm{RT}^{\mathrm{a}}$} & H. polyrhizus & H. undatus \\
\hline & & & \multicolumn{2}{|c|}{ Area (\%) } \\
\hline 1 & $n$-Hexadecanoic acid & 39.85 & 1.46 & 2.37 \\
\hline 2 & 1-Hexadexyne & 44.47 & - & 0.68 \\
\hline 3 & (Z, Z)-9, 12-Octadecadienoic acid & 44.97 & - & 1.62 \\
\hline 4 & 2-Chloroethyl linoleate & 45.01 & 0.38 & - \\
\hline 5 & Oleic acid & 45.19 & 1.17 & 1.25 \\
\hline 6 & Octacosane & 49.61 & 12.2 & - \\
\hline 7 & 17-Pentatriacontene & 50.83 & 1.15 & - \\
\hline 8 & Trichloroacetic acid, hexadecyl ester & 54.71 & - & 5.21 \\
\hline 9 & 1-Nonadecene & 54.79 & 3.17 & - \\
\hline 10 & 6-Tetradecanesulfonic acid, butyl ester & 55.81 & - & 1.25 \\
\hline 11 & 1,2-Benzenedicarboxylic acid, mono (2-ethylhexyl) ester & 56.11 & 0.31 & 0.81 \\
\hline 12 & Phthalic acid, 6-ethyloct-3-yl 2-ethylhexyl ester & 56.19 & 1.21 & - \\
\hline 13 & Eicosane & 59.44 & 3.64 & 1.92 \\
\hline 14 & Tetratriacontane & 59.51 & 1.04 & - \\
\hline 15 & 1-Tetracosanol & 59.80 & 5.19 & - \\
\hline 16 & Heptacosane & 59.93 & 0.44 & 5.52 \\
\hline 17 & Campesterol & 60.97 & 4.16 & 5.27 \\
\hline 18 & Stigmasterol & 62.59 & 1.21 & 2.75 \\
\hline 19 & Squalene & 62.86 & 0.22 & 0.64 \\
\hline 20 & 11-Hexacosyne & 63.07 & 1.24 & - \\
\hline 21 & Octadecanal & 63.18 & - & 3.55 \\
\hline 22 & Nonacosane & 64.52 & 1.43 & 5.02 \\
\hline 23 & Octadecane & 64.87 & 6.27 & 9.25 \\
\hline 24 & $y$-Sitosterol & 65.12 & 9.35 & 19.32 \\
\hline 25 & a-Amyrin & 66.15 & 13.90 & - \\
\hline 26 & Hexadecyl oxirane & 67.55 & - & 1.54 \\
\hline 27 & $\beta$-Amyrin & 67.81 & 15.87 & 23.39 \\
\hline 28 & Ergosta-4,6,8(14),22-tetraen-3-one & 68.24 & - & 1.46 \\
\hline 29 & Docosane & 68.82 & 3.19 & - \\
\hline 30 & Stigmast-4-en-3-one & 69.83 & 4. 65 & - \\
\hline 31 & $\beta$-Sitosterol & 72.84 & 2.46 & - \\
\hline
\end{tabular}


of many components. Table 1 shows the identified compounds (in total, 31 compounds), retention time and percentage obtained by GC-MS. And the molecular structures for the main compounds of these extracts are shown in Figure 1.

A total of 24 components in $H$. polyrhizus extract, representing $90.66 \%$ of the total composition, were identified, of which $29.77 \%$ were triterpenoids and $16.46 \%$ were steroids. Its extract was characterized by a high content of $\beta$-amyrin (15.87\%), $\alpha$-amyrin (13.90\%), octacosane (12.2\%), $\gamma$-sitosterol (9.35\%), octadecane (6.27\%), 1-tetracosanol (5.19\%), stigmast-4-en-3-one (4.65\%), and campesterol (4.16\%).

The predominant constituents of $H$. undatus extract were $\beta$-amyrin (23.39\%), $\gamma$-sitosterol (19.32\%), and octadecane $(9.25 \%)$, which formed approximately a half of the extract. Heptacosane (5.52\%), campesterol (5.27\%), nonacosane $(5.02 \%)$, and trichloroacetic acid, hexadecyl ester (5.21\%) were also present at significant concentration. A total of 19 components were identified, comprising $92.82 \%$ of the total extract. Moreover, its extract was also dominated by triterpenoids (23.39\%) and steroids (19.32\%).

In conclusion, both of $H$. polyrhizus and $H$. undatus contained mostly triterpenoids and steroids. In contrast, the content of triterpenoids in supercritical carbon dioxide extract of $H$. polyrhizus was higher than that of $H$. undatus, whereas the extract of $H$. undatus had higher content of steroids. It would also be worth pointing out that the constituents of the two extracts are normally influenced by several factors such as geographical, climatic, seasonal and experimental conditions.

\section{Cytotoxic activity}

To determine the cytotoxic activity of supercritical carbon dioxide extracts of pitaya $(H$. polyrhizus and $H$. undatus) peel against cancer cell lines PC3 (human prostate cancer cell line), Bcap-37 (human breast cancer cell line), and MGC-803 (human gastric cancer cell line), cytotoxicity MTT assay was carried out, and net growth inhibition was calculated comparing to a negative control growth. Adriamycin (ADM) was used as a positive control. The inhibitory ratios of ADM after $72 \mathrm{~h}$ of treatment at $0.1 \mathrm{mg} / \mathrm{mL}$ against the three cell lines were $97.2 \%, 99.3 \%$, and $98.1 \%$. Of all extracts tested at maximum concentration $(0.7 \mathrm{mg} / \mathrm{mL})$, the inhibitory ratios of $H$. polyrhizus and $H$. undatus extracts were $67.3 \%$ and $60.7 \%$ against PC3 cells, $63.5 \%$ and $62.4 \%$ against Bcap37 cells, and $78.9 \%$ and $55.2 \%$ against MGC-803 cells, respectively. Further experiments found that proliferation of these three cells were significantly inhibited by these extracts in a concentration-dependent manner, as shown in Figures 2 and 3. The $\mathrm{IC}_{50}$ values of $H$. polyrhizus extract on these three cells were 0.61, 0.45, and $0.43 \mathrm{mg} / \mathrm{mL}$, respectively, while for $H$. undatus extract, the $\mathrm{IC}_{50}$ values were $0.64,0.47$, and $0.73 \mathrm{mg} / \mathrm{mL}$, respectively. Thus it can be seen that the inhibitory effect on cancer cells of $H$. polyrhizus was stronger than that of $H$. undatus, especially on MGC-803 cells.

Steroids and pentacyclic triterpenoids are the most important classes of natural products occurring widely in the plant kingdom $[9,10]$. They have been shown to possess several medicinal properties including anticancer and anti-HIV activities [11]. Thao et al. found that $\beta$-amyrin exhibited some cytotoxicity against A549 and HL-60 cancer cell lines with $\mathrm{IC}_{50}$ values of 46.2 and $38.6 \mu \mathrm{M}$, respectively [12]. In 2012, Lin et al. studied the chemical constituents of Rabdosia serra (MAXIM.) HARA, and found $\beta$-sitosterol isolated from the plant have significant cytotoxic activities against HepG-2, MCF-7, and HL-60 cells [13]. Stigmast-4-en-3-one also displayed high antitumor-promoting activity [14]. Thus, to determine whether these compounds were responsible for the activities of these extracts, we evaluated the cytotoxic activities of these compounds against PC3, Bcap-37, and MGC-803 cells. The results are shown in Table 2.

It can be seen from the $\mathrm{IC}_{50}$ values that $\beta$-amyrin, $\beta$-sitosterol, and stigmast-4-en-3-one suppressed proliferation of the above three cancer cell lines in different extents $\left(\mathrm{IC}_{50}\right.$ values of 43.8-79.3 $\left.\mu \mathrm{M}\right)$. These compounds showed similar inhibition activity against PC3 and MGC-803 cells, while the proliferation inhibition of MGC-803 cells was superior to other kinds of cancer cells. However, $\alpha$-amyrin displayed weak activities against the three cells. These finding indicated that

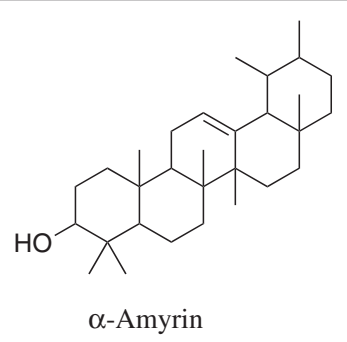

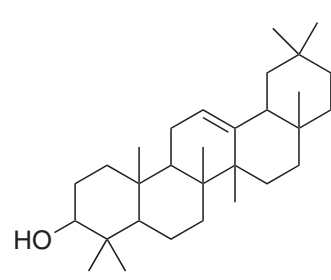

$\beta$-Amyrin

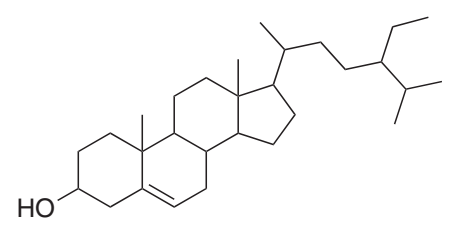

$\gamma$-Sitosterol

Figure 1 The structures of the main components of pitaya peel extracts. 


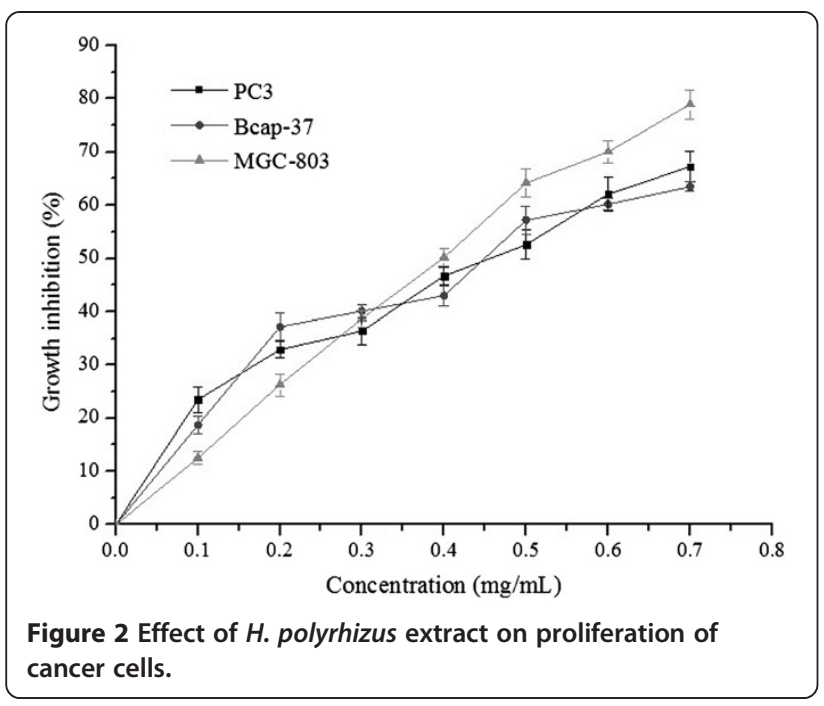

$\beta$-amyrin, $\beta$-sitosterol, and stigmast-4-en-3-one may be responsible for the activities of the two extracts.

\section{Antioxidant activity}

The principle of in vitro antioxidant activity is based on the availability of electrons to neutralize an free radicals $[15,16]$. In this study, the antioxidant activities of supercritical carbon dioxide extracts of $H$. polyrhizus and $H$. undatus were evaluated by DPPH radical scavenging assay, with vitamin $\mathrm{C}(\mathrm{Vc})$ as the positive control. And the negative control group was treated with ethanol. The two extracts and Vc were dissolved in ethanol. Each experiment was repeated at least three times. The scavenging rate of $\mathrm{Vc}$ at $0.1 \mathrm{mg} / \mathrm{mL}$ was $98.9 \%$. DPPH freeradical scavenging properties of the two extracts are present in Figure 4. A lower $\mathrm{IC}_{50}$ value and greater $\mathrm{DPPH}$ radical scavenging percentages indicate higher antioxidant activity. Both of the two extracts exhibited some antioxidant activities. The $\mathrm{IC}_{50}$ values of $H$. polyrhizus and $H$. undatus extracts were 0.83 and $0.91 \mathrm{mg} / \mathrm{mL}$, respectively.

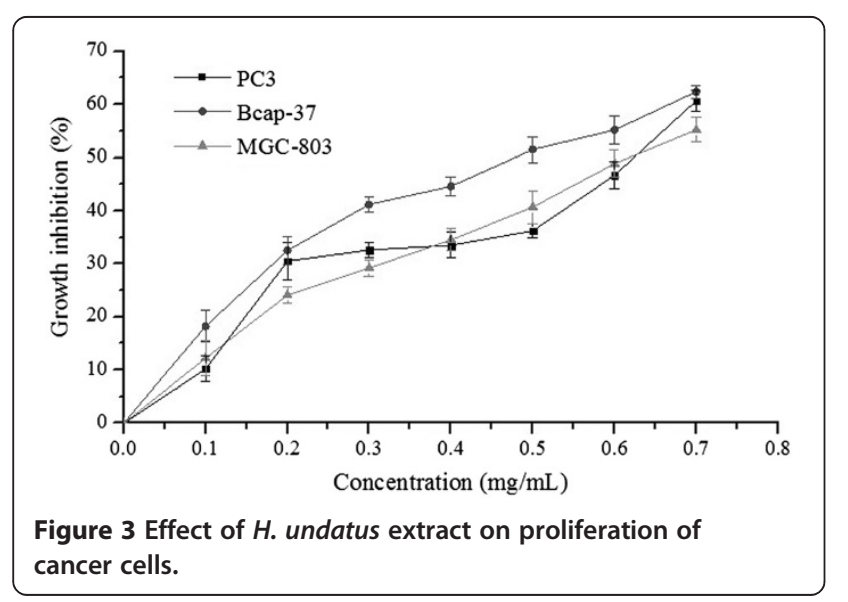

Table 2 Effect of steroids and triterpenoids from supercritical carbon dioxide extracts of $\boldsymbol{H}$. polyrhizus and $H$. undatus against cell viability of different cancer cell lines

\begin{tabular}{llll}
\hline Compound & $\mathbf{I C}_{\mathbf{5 0}}(\boldsymbol{\mu M})^{\mathbf{a}}$ & & \\
\cline { 2 - 4 } & $\mathbf{P C 3}$ & Bcap-37 & MGC-803 \\
\hline a-Amyrin & $>100^{\mathrm{b}}$ & $>100$ & $>100$ \\
$\beta$-Amyrin & $73.2 \pm 1.02$ & $78.4 \pm 0.93$ & $51.9 \pm 0.87$ \\
$\beta$-Sitosterol & $74.4 \pm 0.65$ & $58.2 \pm 0.44$ & $43.8 \pm 0.63$ \\
Stigmast-4-en-3-one & $65.4 \pm 1.13$ & $79.3 \pm 0.49$ & $56.9 \pm 0.81$ \\
ADM $^{c}$ & $1.09 \pm 0.18$ & $1.34 \pm 0.30$ & $0.83 \pm 0.22$ \\
\hline
\end{tabular}

${ }^{\mathrm{a} A g e n t}$ concentration $(\mu \mathrm{M})$ that inhibited cell growth by $50 \%$ at $72 \mathrm{~h}$ after treatment.

${ }^{b}$ When $50 \%$ inhibition could not reached at the highest concentration, then $>100 \mu \mathrm{M}$ was given.

'Adriamycin, positive control.

It also can be seen from Figure 4 that the two extracts showed dose dependent antioxidant activity.

Antioxidants terminate these chain reactions by removing free radical intermediates, and inhibit other oxidation reactions, and they do this by being oxidized themselves [17-19]. High phenolic content were usually correlated with high radical scavenging activity [20]. Choo et al. found that $H$. polyrhizus and $H$. undatus had great antioxidant properties, because of high content of polyphenols [2]. Moreover, polyphenols can be extracted by supercritical carbon dioxide extraction [21]. Hence, antioxidant activities of the pitaya peel extracts were most probably due to the presence of polyphenols, which have the hydrogendonor ability to scavenge the free radicals. However, the polyphenols were not detected by GC-MS. Studies of the content of polyphenols in the extracts are currently underway.

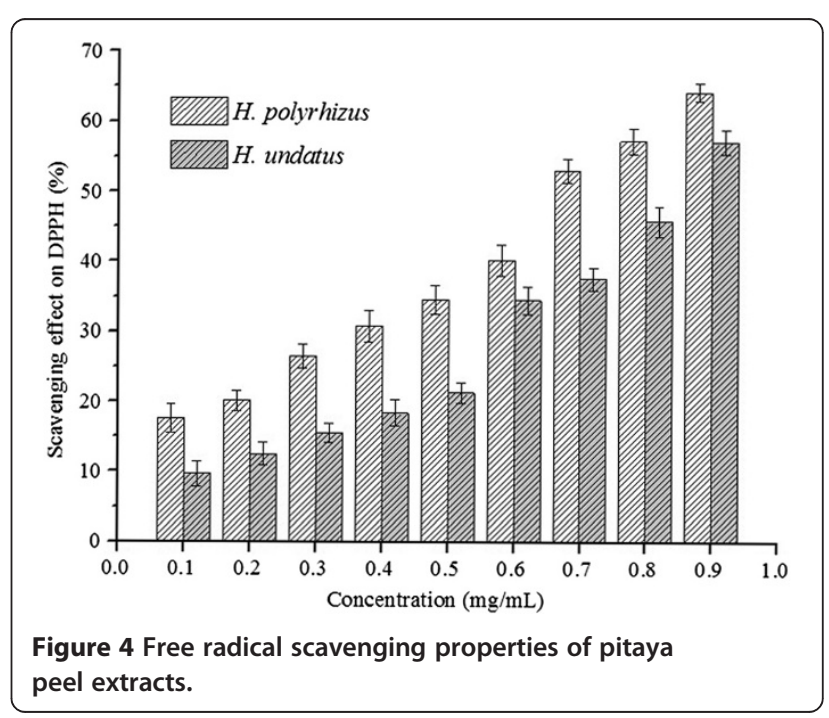




\section{Conclusions}

In summary, the composition of supercritical carbon dioxide extracts of pitaya (H. polyrhizus and $H$. undatus) peel has been analyzed by GC-MS, and their cytotoxic and antioxidant activity were investigated. The predominant constituents of $H$. polyrhizus extract were $\beta$ amyrin (15.87\%), $\alpha$-amyrin (13.90\%), octacosane (12.2\%), $\gamma$-sitosterol (9.35\%), whereas $H$. undatus were $\beta$-amyrin (23.39\%), $\gamma$-sitosterol (19.32\%), and octadecane (9.25\%). The two extracts showed a wild range of cytotoxic activities against PC3, Bcap-37, and MGC-803 cells, and it was found that $\beta$-amyrin, $\beta$-sitosterol, and stigmast-4en-3-one, the main components, were responsible for their activities. In addition, they had some DPPH radical scavenging activities, with $\mathrm{IC}_{50}$ values of 0.83 and $0.91 \mathrm{mg} / \mathrm{mL}$, respectively.

There is a trend to find cytotoxic and antioxidant materials from natural products in the modern medical industry. The above results show that supercritical carbon dioxide extracts of pitaya ( $H$. polyrhizus and $H$. undatus) peel could be a potential source of compounds with cytotoxic and antioxidant activities and the results provide a reference point for further research on the chemical components of supercritical carbon dioxide extracts of pitaya peel as well as for their utilization.

\section{Materials and methods}

\section{General procedures and reagents}

The melting points of the products were determined using an XT-4 binocular microscope (Beijing Tech Instrument Co. Ltd., Beijing, China). ${ }^{13} \mathrm{C}$ NMR were recorded using a JEOL-ECX500 spectrometer at $22^{\circ} \mathrm{C}$, with tetramethylsilane as the internal standard and $\mathrm{CDCl}_{3}$ as the solvent. Column chromatography was performed using silica gel (200-300 meshes) (Qingdao Marine Chemistry Co., Qingdao, China) and Sephadex LH-20 (GE Healthcare Bio-Sciences AB, Uppsala, Sweden). Sodium dodecyl sulfate (SDS) were purchased from Beijing Dingguo CO., Ltd; 2,2-diphenlyl-1-picrylhydrazyl (DPPH) and vitamin C (Vc) were purchased from Aladdin Reagent Inc; 3-(4,5-Dimethylthiazol-2-yl)-2,5-diphenyl tetrazolium bromide (MTT) and DMSO were purchased from Roche Molecular Biochemicals (1465-007); Adriamycin (ADM) was purchased from Zhejiang Hisun Pharmaceutical Co., Ltd; $\alpha$-amyrin, $\beta$-sitosterol, and stigmast-4-en-3-one had been prepared in previous work $[22,23] . \beta$-amyrin was isolated from supercritical carbon dioxide extract of $H$. undatus peel, and its purification process and NMR data are presented in Additional file 1. All other chemicals were of analytical reagent grade and used without further purification.

\section{Plant materials}

Fresh peel of pitaya (H. polyrhizus and H. undatus) were collected from Guiyang, Guizhou province in China, in July 2013. Voucher specimens were deposited at Guizhou Fruit Institute, Guiyang, China.

\section{Supercritical carbon dioxide extraction}

About $250 \mathrm{~g}$ of dried peel of pitaya (H. polyrhizus and $H$. undatus) were cut into pieces and submitted to extraction. $\mathrm{A} \mathrm{CO}_{2}$ flow rate of $30 \mathrm{~L} / \mathrm{h}$ and an extraction period of $60 \mathrm{~min}$ were used. The extraction was performed under a pressure of $30 \mathrm{MPa}$ and at a temperature of $40^{\circ} \mathrm{C}$. The two extracts obtained by supercritical carbon dioxide extraction assay were pale yellowish. These extracts were dried over anhydrous $\mathrm{Na}_{2} \mathrm{SO}_{4}$ and placed at a low temperature in the refrigerator until analysis.

\section{Gas chromatography-mass spectroscopy (GC-MS) analysis} A gas chromatographic-mass spectral analysis was performed on the extracts using an Agilent 6890 GC with Agilent 5973 mass selective detector (EI-MS, electron energy $=70 \mathrm{eV}$, scan range $=10-550 \mathrm{amu}$ ), and a fused silica capillary column (HP-5 ms, $30 \mathrm{~m} \times 0.25 \mathrm{~mm}$ ) coated with $5 \%$ phenyl methyl siloxane $(0.25 \mu \mathrm{m}$ phase thickness). The carrier gas was helium (99.999\%) with a flow rate of $1.0 \mathrm{~mL} / \mathrm{min}$. The injector temperature was $250^{\circ} \mathrm{C}$, and the oven temperature was programmed to $50^{\circ} \mathrm{C}$ for $2 \mathrm{~min}$, and then increased to $290^{\circ} \mathrm{C}$ at a rate of $5^{\circ} \mathrm{C} / \mathrm{min}$. The interface temperature was $280^{\circ} \mathrm{C}$. A $1 \%(w / v)$ solution of each sample in dichloromethane $\mathrm{CH}_{2} \mathrm{Cl}_{2}$ was prepared, and $1 \mu \mathrm{L}$ was injected using a split injection technique with split ratio 20:1. The components were identified by comparison of their mass spectra with those of the NIST 5 mass spectra library.

\section{Cell lines and culture}

PC3, Bcap-37, and MGC-803 cell lines were obtained from the Cell Bank of the Chinese Academy of Sciences (Shanghai, China). The entire cancer cell lines were maintained in the RPMI 1640 medium. They were supplemented with $10 \%$ heat-inactivated fetal bovine serum (FBS). All cell lines were maintained at $37^{\circ} \mathrm{C}$ in a humidified 5\% carbon dioxide and 95\% air incubator.

\section{MTT assay}

All the extracts or compounds were dissolved in DMSO and subsequently diluted in the culture medium before treatment of the cultured cells. When PC3, Bcap-37, and MGC-803 cells were $80-90 \%$ confluent, they were harvested by treatment with a solution containing $0.25 \%$ trypsin, thoroughly washed and resuspended in supplemented growth medium. Cells were plated in $100 \mu \mathrm{L}$ of medium/well $\left(2 \times 10^{3} /\right.$ well $)$ in 96-well plate. After incubations overnight, the cells were treated with extracts or compounds in RPMI 1640 with 10\% FBS for 72 h. In parallel, the cells treated with $0.1 \%$ DMSO served as negative control and ADM as positive control. After 
$72 \mathrm{~h}, 100 \mu \mathrm{L}$ of MTT was added, and the cells were incubated for $4 \mathrm{~h}$. The MTT-formazan formed by metabolically viable cells was dissolved in $100 \mu \mathrm{L}$ of SDS for $12 \mathrm{~h}$. The absorbance was then measured at $595 \mathrm{~nm}$ with a microplate reader (BIO-RAD, model 680), which is directly proportional to the number of living cells in culture [24-26]. The percentage cytotoxicity was calculated using the formula.

$$
\begin{aligned}
\% \text { Cytotoxicity }= & {\left[\left(\text { Control }_{\mathrm{abs}}-\text { Blank }_{\mathrm{abs}}\right)\right.} \\
& \left.-\left(\text { Test }_{\mathrm{abs}}-\text { Blank }_{\mathrm{abs}}\right)\right] \\
& /\left(\text { Control }_{\mathrm{abs}}-\text { Blank }_{\mathrm{abs}}\right) \times 100
\end{aligned}
$$

\section{DPPH free radical scavenging assay}

The DPPH free radical scavenging assay has been widely used to evaluate the antioxidant capacity, which is stable due to its resonance stability and special blockade of benzene rings $[27,28]$. The purple chromogen radical $\mathrm{DPPH}$ is reduced by antioxidant compounds to the corresponding pale yellow hydrazine [29]. The antioxidant activity of plant extracts and antioxidant standard were evaluated on the basis of radical scavenging effect of the stable DPPH free radical. In its radical form, DPPH has a characteristic absorption at $515 \mathrm{~nm}$ in ethanol, which disappears with acceptance of an electron from the antioxidant sample. All tested samples were dissolved in ethanol. $100 \mu \mathrm{L}$ of DPPH in ethanol was added into a 96-well plate, and was mixed with the test samples (100 $\mu \mathrm{L})$ at different concentrations. After shaken for $60 \mathrm{~s}$ in microplate reader, it was left in the dark at $37^{\circ} \mathrm{C}$ for $30 \mathrm{~min}$. The absorbance was then measured at $515 \mathrm{~nm}$ with a microplate reader (BIO-RAD, model 680). All experiments were carried out in triplicate. Ethanol was used as the blank control and vitamin $C$ served as positive control [30,31]. The DPPH radical scavenging activity of the extracts or compounds were calculated according to the following formula.

$$
\begin{aligned}
\% \mathrm{DPPH}_{\text {scavenging activity }}= & \underset{\times 100}{\left(\mathrm{OD}_{\text {blank }}-\mathrm{OD}_{\text {sample }}\right) / \mathrm{OD}_{\text {blank }}} \\
\times 100 &
\end{aligned}
$$

\section{Statistical analysis}

All statistical analyses were performed using SPSS 10.0, and the data were analyzed using one-way ANOVA. The mean separations were performed using the least significant difference method. Each experiment was performed in triplicate, and all experiments were run thrice and yielded similar results. Measurements from all the replicates were combined, and the treatment effects were analyzed.

\section{Additional file}

Additional file 1: Experimental details and data of $\beta$-amyrin. Which includes the experimental procedure, spectroscopic data, and copies of ${ }^{1} \mathrm{H}$ NMR and ${ }^{13} \mathrm{C}$ NMR of $\beta$-amyrin.

\section{Competing interests}

The authors declare that they have no competing interest.

\section{Authors' contributions}

$\mathrm{HL}$ and $\mathrm{YC}$ collected and identified the plant material, and drafted the manuscript. ZP performed the GC-MS analysis, identified the components and drafted the manuscript. TL took part of the bioassay experiments. SY identified the components and took part of the bioassay experiments. All authors read and approved the final manuscript.

\section{Acknowledgements}

The authors wish to thank the Scientific Research of Guizhou (No.20126006) for the financial support.

\section{Author details}

${ }^{1}$ Guizhou Fruit Institute, Guizhou Academy of Agricultural Sciences, Guiyang 550006, P R China. ${ }^{2}$ Research Institute of Traditional Chinese Medicine, Yangtze River Pharmaceutical Group Beijing Haiyan Pharmaceutical Co., Ltd, Beijing 102206, P R China. 3State key Laboratory Breeding Base of Green Pesticide and Agricultural Bioengineering, Key Laboratory of Green Pesticide and Agricultural Bioengineering, Ministry of Education, Guizhou University, Guiyang 550025, P R China.

Received: 15 December 2013 Accepted: 30 December 2013 Published: 3 January 2014

\section{References}

1. Jaafar RA, Rahman ARBA, Mahmod NZC, Vasudevan R: Proximate analysis of dragon fruit (Hylecereus polyhizus). Am J Appl Sci 2009, 6:1341-1346.

2. Choo WS, Yong WK: Antioxidant properties of two species of Hylocereus fruits. Adv App/ Sci Res 2011, 2:418-425.

3. De Freitas ST, Mitcham EJ: Quality of pitaya fruit (Hylocereus undatus) as influenced by storage temperature and packaging. Sci Agric 2013, 70:257-262.

4. Rebecca OPS, Boyce AN, Chandran S: Pigment identification and antioxidant properties of red dragon fruit (Hylocereus polyrhizus). Afr J Biotechnol 2010, 9:1450-1454.

5. Esquivel P, Stintzing FC, Carle R: Phenolic compound profiles and their corresponding antioxidant capacity of purple pitaya (Hylocereus sp.) genotypes. Z Naturforsch C 2007, 62:636-644.

6. Nurliyana R, Syed Zahir I, Mustapha Suleiman K, Aisyah MR, Kamarul Rahim K: Antioxidant study of pulps and peels of dragon fruits: a comparative study. Int Food Res J 2010, 17:367-375.

7. Herbacha KM, Stintzinga FC, Elssb S, Prestonb C, Schreierb P, Carlea R: Isotope ratio mass spectrometrical analysis of betanin and isobetanin isolates for authenticity evaluation of purple pitaya-based products. Food Chem 2006, 99:204-209.

8. Herbach KM, Stintzing FC, Carle R: Identification of heat-induced degradation products from purified betanin, phyllocactin and hylocerenin by high-performance liquid chromatography/electrospray ionization mass spectrometry. Rapid Commun Mass Sp 2005, 19:2603-2616.

9. Janeczko A: The presence and activity of progesterone in the plant kingdom. Steroids 2012, 77:169-173.

10. Nicholas HJ: Biosynthesis of $\beta$-sitosterol and pentacyclic triterpenes of Dalvia officinalis. J Bio Chem 1962, 237:1676-1680.

11. Patocka J: Biologically active pentacyclic triterpenes and their current medicine signification. J App/ Biomed 2013, 1:7-12.

12. Thao NTP, Hung TM, Lee MK, Kim JC, Min BS, Bae K: Triterpenoids from Camellia japonica and their cytotoxic activity. Chem Pharm Bull 2010, 58:121-124.

13. Lin L, Gao Q, Cui C, Zhao H, Fu L, Chen L, Yang B, Luo W, Zhao M: Isolation and identification of ent-kaurane-type diterpenoids from Rabdosia serra (MAXIM.) HARA leaf and their inhibitory activities against HepG-2, MCF-7, and HL-60 cell lines. Food Chem 2012, 131:1009-1014. 
14. Habsah M, Ali AM, Lajis NH, Sukari MA, Yap YH, Kikuzaki H, Nakatani N: Antitumour-promoting and cytotoxic constituents of Etlinera elatior. Malays J Med Sci 2005, 12:6-12.

15. Okoh OO, Sadimenko AP, Afolayan AJ: Antioxidant activities of Rosmarinus officinalis $\mathrm{L}$. essential oil obtained by hydro-distillation and solvent free microwave extraction. Afr J Biotechnol 2011, 10:4207-4211.

16. Yang $C H$, Li RX, Chuang LY: Antioxidant activity of various parts of Cinnamomum cassia extracted with different extraction methods. Molecules 2012, 17:7294-7304.

17. Nazrulislam M, Pervin S: Antioxidants. J Dhaka National Med Coll Hos 2011 $17: 61-64$

18. Hamid AA, Aiyelaagbe OO, Usman LA, Ameen OM, Lawal A: Antioxidants: its medicinal and pharmacological applications. Afr J Pure Appl Chem 2010, 4:142-151

19. Chakraborty P, Kumar S, Dutta D, Gupta V: Role of antioxidants in common health diseases. Res J Pharm Tech 2009, 1:239-244.

20. Li W, Shan F, Sun S, Corke H, Beta T: Free radical scavenging properties and phenolic content of Chinese black-grained wheat. J Agric Food Chem 2005, 53:8533-8536.

21. Cavalcanti RN, Navarro-Díaz HJ, Santos DT, Rostagno MA, Meireles MAA: Supercritical carbon dioxide extraction of polyphenols from pomegranate (Punica granatum L.) leaves: Chemical composition, economic evaluation and chemometric approach. J Food Res 2012, 1:282-294.

22. Yang S, Zhao Q, Xiang H, Liu M, Zhang Q, Xue W, Song B, Yang S: Antiproliferative activity and apoptosis-inducing mechanism of constituents from Toona sinensis on human cancer cells. Cancer Cell Int 2013, 13:12.

23. Yang $S$, Liu M, Liang $N$, Zhao Q, Zhang Y, Xue W, Yang S: Discovery and antitumor activities of constituents from Cyrtomium fortumei (J.) Smith rhizomes. Chem Cent J 2013, 7:24

24. Li YH, Fu HG, Su F, Gao LM, Tang S, Bi CW, Li YH, Wang YX, Song DQ: Synthesis and structure-activity relationship of 8-substituted protoberberine derivatives as a novel class of antitubercular agents. Chem Cent $J$ 2013, 7:117.

25. Li S, Chou G, Hseu Y, Yang H, Kwan H, Yu Z: Isolation of anticancer constituents from flos genkwa (Daphne genkwa Sieb.et Zucc.) through bioassay-guided procedures. Chem Cent J 2013, 7:159.

26. Banerji B, Pramanik SK, Pal U, Maiti NC: Potent anticancer activity of cystine-based dipeptides and their interaction with serum albumins. Chem Cent J 2013, 7:91.

27. Biswas M, Haldar PK, Ghosh AK: Antioxidant and free-radical-scavenging effects of fruits of Dregea volubilis. J Nat Sci Biol Med 2010, 1:29-34.

28. Motlhanka DMT, Habtemariam S, Houghton P: Free radical scavenging activity of crude extracts and 4'-O-methylepigallocatechin isolated from roots of Cassine transvaalensis burtt-davy from Botswana. Afr J Biomed Res 2008, 11:55-63.

29. Rao KS, Keshar NK, Kumar BR: A comparative study of polyphenolic composition and in-vitro antioxidant activity of Illicium verum extracted by microwave and soxhlet extraction techniques. Ind J Pharm Edu Res 2012, 46:228-234.

30. Shami AM, Philip K, Muniandy S: Synergy of antibacterial and antioxidant activities from crude extracts and peptides of selected plant mixture. BMC Complem Altern M 2013, 13:360.

31. Moniruzzaman M, Sulaiman SA, Khalil Ml, Gan SH: Evaluation of physicochemical and antioxidant properties of sourwood and other Malaysian honeys: a comparison with manuka honey. Chem Cent J 2013, 7:138.

doi:10.1186/1752-153X-8-1

Cite this article as: Luo et al: Chemical composition and in vitro evaluation of the cytotoxic and antioxidant activities of supercritical carbon dioxide extracts of pitaya (dragon fruit) peel. Chemistry Central Journal 2014 8:1.

Publish with ChemistryCentral and every
scientist can read your work free of charge
"Open access provides opportunities to our
colleagues in other parts of the globe, by allowing
anyone to view the content free of charge."
W. Jeffery Hurst, The Hershey Company.
- available free of charge to the entire scientific community
- peer reviewed and published immediately upon acceptance
- cited in PubMed and archived on PubMed Central
- yours - you keep the copyright
Submit your manuscript here:
http://www.chemistrycentral.com/manuscript/

